\title{
Dealing with difference and dissensus within the church as organisation
}

M Painter-Morland

(Centre for Occupational Ethics, University of Pretoria)

\section{ABSTRACT \\ Dealing with difference and dissensus within the church as organisation}

This paper wants to propose a way of dealing with the reality of difference within churches that allows for unity amidst diversity. It argues for the adoption of institutional frameworks that function as guiding and unifying forces without becoming repressing, totalising structures. The presence of dissensus and difference does not necessarily have to result in the fragmentation of churches. In fact, when harnessed effectively, difference and dissensus can become a valuable resource for renewal and realignment within churches. The paper develops a framework for dealing with diversity that binds people to the church as organisation in a way that respects their individual value-configurations and input. In the first place, it argues for a holistic view of the relationship between bodiliness, nature, technology, language, and truth statements. In the second place, it insists that confessional, spiritual and moral guidelines should neither be totalising structures that repress difference, nor oppositional differences that exclude commonality. In the third place, it argues that ongoing connectedness between individual members of the church is necessary. Individuals must see themselves as part of an everchanging, ever-evolving web of relations. Guidelines for dialogue within the church therefore become essential.

\section{INTRODUCTION}

Ever since Jesus called his first disciples, Christian believers have organised themselves in communities of faith. In the course of history these communities have taken on numerous forms and manifestations. The numerous and multifarious churches that are part of our present reality is the product of this long history of development, adaptation, conflict, differentiation and interaction. These intellectual, social, political, moral and spiritual processes and forces are not just something of the past, they continue to shape and reshape the institutional reality of the present-day church. Difference and dissensus is not only the hallmark of inter-church relations, but also increasingly of intra-church 
relations. Individual differences with regard to confession, spirituality and morality amongst its members have become a major challenge to the institutional unity of many churches.

This paper wants to propose a way of looking at and dealing with the reality of difference within churches which allows for unity amidst diversity. It argues for the adoption of institutional frameworks that function as guiding and unifying forces without becoming repressing, totalising structures. The presence of dissensus and difference does not necessarily have to result in the fragmentation of churches. In fact, when harnessed effectively, difference and dissensus can become a valuable resource for renewal and realignment within churches.

Apart from its other dimensions, most churches also display some form of organisational structure. It is in this, its organisational manifestation, that churches display many of the characteristics of secular organisations. In considering a church as an organisation it is imperative that one develops an understanding of and sensitivity for the individuals, groups, power relations and truths that exist within it. It is important because in the business sphere one often finds that an organisation's view of its corporate identity, as well as the identity of individuals and groups who work and function within it, have direct bearing on the way it is structured and operates. In recent organisational studies a number of paradigm shifts have taken place with regard to individual and corporate identity with important implications for the way diversity is dealt with. These paradigm shifts have given rise to a number of alternative perspectives with regard to how individual differences and organisational unity can be balanced and maintained. It is precisely these insights that churches could and should utilize to develop a form of organisational integrity that does not suffocate difference and dissensus.

\section{NEW VIEWS ON THE NATURE OF INDIVIDUAL AND ORGANISATIONAL IDENTITY}

\subsection{Identity configurations}

The modernist concept of the integrated self, with the ego acting as master of the household, seeking to integrate the competing demands it faces, made sense in terms of the modern ideals of unified wholeness, progression, and the theories of governance and authority within the Western world. With these ideals disintegrating at the end of the 20th century, different ideas of identity have started to develop. The posthumanist, poststructuralist alternative makes room for a subject who is multidimensional and without a center or hierarchical integration. Instead of referring to a subject's "core" or assuming a "centered self", most people display distributed selves. This means that identity is constituted by the unique configuration of various traits, perceptions, assumptions, and value-systems within the individual.

One of the implications of the multidimensional or distributed self is that the particular way in which the individual's identity-configurations is activated, is not predictable. Most people operate according to a relational subjectivity, in which their relationships with others and their interaction within certain contexts allows them to "change gear" or to shift their emphases in terms of what constitutes their identity in any given situation. The particular configuration of values that the individual will draw on in any given circumstance cannot be pre-determined. An individual's selection of significant values remains quite unpredictable and random.

Hassard (1993:15) indicates that the grand isolation of the modern subject has been replaced by the notion of agency as a system of relations between strata. Instead of being self-directing, the subject now becomes the convenient location for the flow of various discourses. Because the agent of propositions and actions is seen as a de-centered subject, who is not the center of the universe and whose decisions and actions are not the sole determinant of events, the role and function of managers or, in the case of churches, church leaders, could be interpreted in a very different way. The words of managers or leaders are like authorless texts; once they have been set in motion, the manager or leader ceases to control its exact meaning. Relational theory suggests that managers' or leaders' "rationality" becomes the product of collective action.

Power is a matter of "social interdependence" and is affected through the coordination of actions around specified definitions. Power, as Foucault (1994:262) explains, is more than just the repressive force that distorts what and how we know. Power produces the way we know ourselves. Power here constitutes us as self-aware subjects, able to know and act on ourselves and on each other (Deleuze 1988:103). But because power is fragmented in its operations, the variety of discourses present in the individual's identity configuration leads to a continual "re-articulation" of individual identity (Brewis 1998:63). In order to understand our decisions and actions, one therefore has to unravel the complex character of our relationships with ourselves, the effect of our exposure to various discourses and our resistance to them.

The search for timeless, universal truths is therefore abandoned in favour of an approach which sees truth as a discursive construction, or a particular way of being which is no more or less "true" than any other. Does this preclude any form of meaning construction or "truth" judgement? No, confessions and ethical statements should rather be seen in a different light. Foucault would for instance describe an ethical pursuit as 
a process by which the individual becomes conscious of the processes of self-formation at work in him/herself, as well as in other people. Therefore, confessional, spiritual, and moral deliberation becomes a process of self-policing and self-conscious self-analysis rather than the process of conforming to rigid, dogmatic positions, conventionalised spiritual practices and abstract ethical codes. The value of this self-conscious activity lies precisely in the fact that we are willing to put ourselves at risk, question our own prejudices, and break through the isolation and obsession with self-interest that could so easily result from the fragmented world we inherited from the world of modern specialization (Brewis 1998:65).

This view of identity has definite implications for churches. Instead of viewing a church as a group of people who all share exactly the same ideas based on universal truths, individual identity configurations are valued and used as a positive resource for discourse within the church as organisation. As has been pointed out, the fact that churches as organisations refrain from providing timeless, universal answers to all confessional, spiritual and moral questions does not necessarily preclude the formation of meaningful "truths" or the moral and spiritual evaluation of certain acts and practices. The crucial point is that the context, the identity-configurations of those involved, and the interests of a variety of stakeholders and discourses are taken into account. The importance of deliberation is in fact enhanced, the discourse enriched, and intellectual, spiritual and moral discernment in churches are sharpened. Managers or leaders within churches become the facilitators of this process, who are in fact part of the process instead of the authors of it. The dichotomy between clergy and lay people within churches dissolves in the web of relationships, within which all church members are formed and transformed.

\subsection{Unity and unapologetic dialogue}

One can identify two ways of dealing with diversity and dissensus. One way would be to isolate distinct groups in terms of certain essential characteristics. Another would be to allow diversity to exist within the group and to encourage dialogue between different positions. Two corresponding forms of postmodern strategies emerge from amongst the host of writings labeled "postmodern". Whereas the first form of postmodernism emphasises fragmentation and the incommensurability of distinct life-forms and groups, other postmodernists argue that every self and every group is not a distinctly identifiable unity, but rather an eclectic configuration of very specific and contextual characteristics. The former ends in fragmentation, while the latter tries to deal with difference in and amongst people in creative ways.
Falzon (1998:91) argues that postmodern strategies should go beyond fragmentation. Postmodernism is often thought of as a strategy which treats differences in a relativistic way by emphasizing fragmented, incommensurable world-views, each with their own unitary and allembracing form of thought and action. Such a viewpoint sustains the metaphysical notion of unity, since it assumes that certain structures display certain essences of ideas and theories, which exist separately from other isolated structures. This view betrays an important aspect of the postmodern movement, which defies abstract, universal structures. This version of postmodernism that Falzon (1998:93) calls the postmodernism of fragmentation, is also strongly reminiscent of the liberal position, one of the positions that other forms of postmodernism aims to surpass. The liberal position tolerates difference and diversity by essentialising the identity of groups and keeping that identity intact. This constitutes a failure to acknowledge our existence in dialogical relations with others, and therefore arrest the ongoing dialogical interaction of competing interpretations that organise and reorganise one another. Kirsten (1988) refers to this strategy as a "postmodernism of reaction", which displays certain neoconservatist tendencies.

An alternative version of postmodernism argues for a dialogical position that holds even seemingly contradictory viewpoints together in a creative tension. This view of dealing with diversity within a church however has two distinct implications. In the first place it has implications for a church's view of itself as a unique confessional community that adheres to a certain truth that excludes certain other truths. This implies that a church may want to identify certain truth elements that it views as non-negotiable for entry into its confessional community. In the second place it has implications for a church's interaction with other faith communities, as well as its interaction with individual church members who have conflicting views.

This paper does not intend to provide arguments for certain truth statements or to advocate a certain view of interreligious dialogue. The question that should, however, be addressed is, how a church is to decide on the basic truth statements that constitute the identity of the organisation. One way of creating unity in a church, while allowing different interpretations of truths and moral guidelines, is by ensuring that those elements that are used to create unity and commonality within the congregation are very minimalist. For instance, stressing the central position of Christ, his offer of God's grace, the imperative to love, and the Bible as Word of God and source of life, may offer a sufficient basis for unity. These statements do not, however, rule out different interpretations of how a church should go about doing its work in the community. It avoids supporting only one interpretation of Scripture on certain confessional, 
spiritual and moral issues. It wants to create unity, but a unity with plenty of room for diversity.

Minimalist truth statements should not be misunderstood as an effort to create at least some semblance of complete consensus in a church. Far from ruling out certain interpretations through the endorsement of these initial points of departure, these generalised statements are an acknowledgement of the fact that confessional, spiritual and moral statements are always subject to interpretation. People have to decide for themselves what it means to say that Jesus Christ is your only hope, or what it means to live by God's grace. They have to find their own way of using the Bible as a source of true life. From the way in which these statements are actualised in practice, it becomes clear that they leave a lot of room for different interpretations. Does the fact that the Bible is seen as the source of true life support a fundamentalist view of the mechanical inspiration, or could it also reflect a more historical critical interpretation of Scripture? One could argue that in numerous respects, churches need not chose one over and against the other, but should rather create room for both. Complete consensus on how these statements should be interpreted need not be the basis for unity in a church.

Following the kind of postmodern approach that this paper proposes, a church would shift its focus away from efforts to provide its members with clear-cut confessional, spiritual and moral directives and concentrate instead on assisting them in generating their own solutions. This means that churches should refrain from top-down rhetoric. Churches should rather engage in a process of challenging individuals to develop their own position on their own terms, and to defend their views on an issue. Churches should even be willing to take risks in the process. If it consistently allows all kinds of spiritualities and theological viewpoints to find its place within the organisation, one cannot guarantee that differences on the appropriateness of certain spiritual events or versions of truth will not occur. The postmodern trait of recognition and protection of "Otherness" does have implications in terms of the loss of predictability and control. It does, however have its benefits in terms of ongoing discourse, adaptability to changing contexts, and creating responsible and empowered church members.

\subsection{Dealing with power, knowledge and self within the church as orga-nisation}

Power-relations were for ever changed with the realisation that no single grand narrative provides a comprehensive and coherent explanation of social reality. This represented the internal erosion of the legitimacy principle of knowledge. The process of delegitimisation was ironically fuelled by the demand of legitimization itself, since more and more language games entered the race to provide the perfect legitimization, in the end only proving the futility of all pursuits of final knowledge. The social subject itself seems to dissolve in the dissemination of language games. The social bond is linguistic, but is not woven with a single thread. Rather it is a fabric formed by the intersection of an indeterminate number of language games (Lyotard 1984:3).

The question that becomes a pressing concern, is whether the loss of the grand narrative dooms us to relativity and nihilism. Does the deconstruction of the power of the grand narrative render us powerless in the flux of varying language games? It depends on one's view of power. If power is seen as the ability to dominate, repress and unify contradictions within a seamless whole, we have indeed become powerless. But power is not intrinsically repressive. Rorty (1994:63) indicates the similarities in the positive view of power in the work of both Foucault and Dewey. Foucault's vision of discourse as a network of power-relations and Dewey's vision of it as instrumental, as one element in the arsenal of tools people use for gratifying, synthesising and harmonising their desires, indicate that power can be a positive force in working out the praxis of living together in an ever shrinking world.

The social bond within a church as an organisation is certainly not woven by a single thread. It is a fabric formed by the intersection of an indeterminate number of language games. This complexity does not necessarily result in nihilism and flux within which people are rendered powerless. Power, in the sense of dominating and controlling, is untenable, but power, in the sense of empowering, setting free and risking unpredictability, could be a particularly productive force. The implication of the relationship between power and knowledge is that power exists as a condition rather than as a property. Knowledge is constituted as an outcome of the systemic articulations of language grounded in social practice. Power is therefore implicit in all aspects of organisational discourse, structuring the rules and the procedures that determine different forms of knowledge. Therefore, it is involved in the delimitation of what can and what cannot be said, the definition of distinct fields and the emergence of various "subject positions", which distributes and hierachises the field of unequal relations. Discourses emerge as regulated systems of statements that have both ideational content and implications for social practice. An organisational culture, therefore, functions as a discourse that establishes certain internal and external boundaries (Linstead 1993:63). These functions can be abused in order to exclude certain voices from the organisational discourse. Yet, from a postmodern perspective, this will be a return to grand narratives that will eventually stifle organisational growth. Rather, discourses should be seen as something that can be reproduced, can be resisted and is subject to change and 
negotiation. Care must be taken to create the conditions that enable the continual reproduction of organisational forms as ongoing discourses, in order to facilitate growth and adaptability to changing environments.

An enquiry into the origins and development of the terms "organisation" and "culture" reveals that they were initially used as verbs, and not as nouns. To use "organisation" solely as a noun is to ignore the fact that it is first and foremost a verb and therefore a practical accomplishment (Parker 2000:50). Nowadays culture is usually used in reference to a state of affairs or an entity, but its medieval meaning was that of a process, that is the tending of natural growth, or cultivation. When one looks at organisational culture from this perspective, it becomes clear that it is responsible for structuring the memories, identities and analogies of those who participate in it. These memories, analogies and identities, indeed, only really make sense within such a framework. Culture provides a skeleton of assumptions and a historical context. In the process of structuring the world in this way, one makes use of language, which as the poststructuralist argues so convincingly, has an endless array of possible meanings, depending on the context. What's more, language can be used in a wide variety of ways. Regional, occupational, ethnic and other divisions give rise to particular local lexicons, turns of phrase and grammatical constructions. These are subsets of the overall language and are usually referred to as "dialects". Organisational cultures both resemble and deviate from the general context, and are therefore both similar and unique. Every organisation responds to the generalisable "structural pressures" of the broader society, such as the economy and culture, but at the same time each organisation mediates and reproduces these pressures in a local manner (Parker 2000:92). Organisations are institutions that structure individual experience, but they themselves are also structured by individual experience. This suggests multiple crosscutting dialects, and hence many possible interpretations of the "cultures of" the organisation. Members define their particular organisational culture when they describe it in their vernacular dialect. The interpretive strategies that members and analysts employ to classify sameness and difference therefore become of paramount importance to describing organisational culture. Yet, it has to be acknowledged that the actors within the organisational environment are heterogeneous and that it therefore becomes essential to situate any description within a historical context. Culture, structure, and power are described by Parker (2000: 94) as contested relations, not material things. This, however, does not mean that they cannot "do" things to achieve various projects, or that they do not represent strong forces within the organisation.
Postmodern organisational theory emphasises the paradoxical nature of organisation. Not only does it hold together a range of unique individuals with a variety of skills, competencies and backgrounds, but it also links a number of diverse functions with one another whilst interacting with a constantly changing environment. Traditional organisational theory values "shared meaning", because it views the organisation as a definitive cultural form that should embody the consensus. Postmodern organisation theory stresses the fact that shared meaning is in reality impossible, and always incomplete. Shared meaning is nothing more than the deferral of difference. When organisational culture is viewed in this way, one should expect it to be paradoxical. In fact, strong cultures may be an indication of strong internal division.

A further characteristic of postmodern organisations is that they are able to hold together a diverse range of unique individuals and functions, while interacting with an ever-changing environment. The process of transformation in churches should not be considered temporary. The goal should not be to arrive at some permanent state of affairs. In fact, the culture displayed in the transformation period is "culture" in the true sense of the word. Because culture is a process, it is the tending of natural growth, or cultivation. This process should never stall in some final form. An organisational culture that is contested, responsive and ever changing will enable a church to deal with the diversities and contextual challenges that it faces.

Acknowledging that a church is an ever-evolving entity, implies that its confession and moral guidelines should always be seen as contextual responses to real-life communities and problems. This "transforming" character of a church need not be a threat to its confessional integrity and result in a type of "situation-ethics". Rather, this process of transformation involves a dialogue between the traditions of a church, the unique value-configurations of the individuals and groups who constitute a church, and the context within which it operates. None of these elements have priority over the other. In fact, it is precisely in and through their interaction that living truth with real-life solutions come into existence.

\section{FRAMEWORK FOR DEALING WITH CONFESSIONAL, SPIRITUAL AND MORAL DIFFERENCE AND DISSENSUS IN THE CHURCH}

\subsection{A holistic view of the relationship between bodiliness, nature,} technology, language, and truth statements is necessary

Thinkers such as Merleau-Ponty, and contemporary writers such as Lakoff and Johnsson emphasise that truth statements are not the product 
of transcendental rationality but rather have to do with the embodied nature of human beings. It is about survival, and serves the purposes of both organisations and individuals. Related to this is the fact that our perceptions of the world is not something we can divide into tidy categories such as facts and values, public and private, professional and personal. Our perceptions of the world can more accurately be described as "universal flesh", or as a network of relationships. Things commonly thought to be "objective" realities, may in fact be just further dimensions of variation. This has some bearing on our view of language as a relational network. Words indicate the differences between signifiers, and are not "pictures" of reality as the earlier Wittgenstein had us believe. Rather, words are part of language-games by which we define and redefine meaning in the ongoing play of signifiers.

Differences that may have determined the categories by which we divided our world and ourselves in the past are now acknowledged as interfaces. The religious, political, social ethical and economical are interfaces of the same reality rather than separate spheres governed by separate rules. Churches can no longer maintain the distinctions between holy and profane, between the religious sphere and secular realities. The world in which churches operate is indeed one of interfaces within which binary oppositions have become obsolete.

Churches as organisations represent contextual realities, and therefore form part of the "universal flesh" that ties everything into a complex web of relationships. Churches have to find their roles and make their contributions within the messiness of these realities. Unambiguous universal directives have become ineffectual and inadequate vehicles for dealing with a world where interconnectedness creates complex structures that continue to surprise us with unprecedented, unpredictable problems and challenges. Within this reality, churches must empower their members by encouraging them to approach the challenges that face their communities from a holistic perspective. They must be able to analyse the context they live in, identify the complex relationships that form part of the problem, and develop multi-faceted solutions.

Churches should emphasise the fact that religious activities are part of people's everyday lives. This holistic approach should not only assist people in integrating their faith experience with the rest of their lives, it should also enable churches to utilize their members' occupational strengths, such as their knowledge and expertise, and empower them to determine their churches' direction and activities. A truly holistic faith experience allows church members to integrate the diverse aspects of their lives. Many churches embark on building projects that serve as an indication of the church's commitment to a holistic ministry. Instead of single purpose church-buildings, these churches are building community centers, which present its members with the opportunity to worship, socialise, gain knowledge and skills, and serve the community. One example of such an initiative is a Johannesburg congregation that has recently unveiled its plans to build a one-stop community center that will house a big worship-center, a small 24-hour chapel, a bookshop, coffee shop, conference facilities, job creation resources, a day-care center, and a kitchen for feeding the hungry.

"Church" should no longer be associated with one or two services on a Sunday, it should be an everyday part of the community. The church as organisation should, therefore, first and foremost respond to the community's needs and interests, instead of dogmatically insisting that the congregation adhere to the prescribed functions of a church. No church function or project is therefore imposed top-down on the church community.

\subsection{Confessional, spiritual and moral guidelines should neither be dealt with as totalising structures that repress difference, nor as oppositional differences that exclude commonality}

The relational character of confessional spiritual and moral perspectives implies that people define "the true", "the edifying" and "the good" as a result of complex interactions. Positive/negative feedback, evaluation and re-evaluation and effective relationships all play a role in an individual's conception of what is true, edifying, or good. Discourse is the process by which people define and redefine their positions in terms of the nature and purpose of their individual and collective pursuits. These positions form webs of relations by which individuals are aligned to the collective, but from which they can also distance themselves as they develop new insights. The concept of "Mitsein" designates the interaction with others that determines one's perspectives and disposition. This process assumes and relies on an ongoing dialogue as to which perspectives are held in common by the collective and what constitutes "free space", within which the individual can hold private views, beliefs and norms. It allows the individual some latitude for dissociation whilst acknowledging the possibility that there should be a sufficient measure of agreement. In some cases, the individual may, however, have to sever his or her ties with the collective.

To allow for the fact that every context, situation, and person is unique and that there is therefore no one irrefutable position, truth should be seen as a function of networks of relations instead of consisting of universal non-negotiable essences. Therefore, no single perspective should enjoy absolute priority or exclusive consideration. For instance, when dealing with an ethical dilemma, guidelines should be used as precisely that - something to guide people in their moral deci-

ISSN 1609-9982 = VERBUM ET ECCLESIA Jrg 22 (1) 2001 
sion-making, and not in a prescriptive or deterministic way. Advice should be sought, various perspectives should be considered, contextual variables should be taken into account. On-going discussion is the key to developing intellectual, spiritual and moral discernment. Dissent should be welcomed as part of the creation of strong confessional, spiritual and moral discourses and differences should be discussed. Doubts and uncertainty must not be viewed as weaknesses, but rather as seriousness and commitment.

For instance, churches should deal with moral issues such as premarital sex and homosexuality in a way that does not repress difference and dissensus. The aim should not be to provide people with unambiguous moral directives based on some unshakable dogmatic conception of truth. However, opposing viewpoints need not completely undermine the sense of community that exists within a congregation. Instead of endorsing one view, which may exclude another, churches should assist their members in thinking through issues. They could do this by helping people ask meaningful questions about issues and by discussing different scriptural perspectives on the issue. The goal of this process, however, is still not to reach absolute consensus.

The challenge facing churches is to empower their members to use their unique identity-configurations to deal with questions and problems, while at the same time providing them with guidelines that may assist their decision-making. The balance between giving enough guidance, but not too much, is essential. In today's fast-paced reality, church members should be weaned from the expectation that a church, or some theologian, can provide them with infallible answers to all their questions and problems. Church members should be taught discretion, discernment, moral decision-making skills and creativity in the face of adversity. Only in this way will churches have any real impact within the "universal flesh" of the global village

\subsection{Remaining connected}

Individuals must see themselves as part of an ever-changing, ever-evolving web of relations with which they may associate. These webs function according to the following precepts: 1) It relies on the principle of freedom of association: the individual must choose to be part of the web of relations based on certain shared conceptions of the good. 2) It must allow for moral free space. The individual must be allowed to be different from the collective in certain respects, without being judged or rejected because of it. The individual must be acknowledged as a "distributed self" who is more than that which he/she shares with the collective, and should be appreciated as such. 3) Diversity must be appreciated and acknowledged as strength, since it is only through difference that intersubjective interaction succeeds in correcting self-confirming, illconsidered, and uninformed perspectives, as well as self-interested behavior and unbridled quests for power.

One of the main threats within the context of confessional, spiritual and moral dissensus is the isolated individual, or the so-called self-maximising individual of late-modernism. These individuals have internalised the division between various life-worlds advocated during the peak of the modernist era to such an extent that confessional, spiritual and moral considerations are limited to the private sphere and any interaction with and responsibility towards others are excluded. When combined with a form of pragmatism that allows a measure of relativism, this radical individualism may lead to a dangerous form of subjectivity. Relativism can only be tolerated in a context in which individual subjectivity is continually decentered through interaction with Others. Both the ideas of Levinas (1985) and Caputo (1993) are relevant here. Levinas describes what he calls "the face of the Other" that calls one to responsibility. He also alludes to the powers a transcendental force (God), who breaks through my subjectivist closure through the face of the Other (Taylor 1994:212). Caputo (1993:83) refrains from appealing to God or any transcendental force, but acknowledges an obligation that bounds one, overtakes one, when one is confronted with the Other. It seems then, that intersubjectivity, whether through dialogue or the presence of the Other in some other form, is the only way to avoid subjectivist closure.

Anti-subjectivist theories are often accused of deconstructing and thereby undermining human attempts to make the world comprehensible and livable, without replacing it with another strategy for coping with the realities of the human condition. How does one, for instance, deal with the problem of confessional, spiritual and moral dissensus in pluralistic communities in a viable, postmodern way? I would like to suggest an intersubjective strategy of unapologetic dialogue. "Unapologetic" must be understood in two ways: it involves witnessing to one's own religious, cultural, political (etc.) values without excuse, but it is also unapologetic in the sense that it is not an exercise in apologetics. One should not be pitting all one's emotional and rational powers against another set of values or beliefs. Religions and cultures should no longer be seen as competing value-systems, but rather as ways in which a pluralistic society can be infused with mutually enriching perspectives. As Streng (1993:97) argues: "...once we allow conceptions of selfhood, and procedures for self-consciously identifying authentic selfhood, other than those given in our immediate cultural context, we can appreciate alternative modes of actualizing an authentic self."

Unapologetic dialogue tries to promote intersubjectivity, but distances itself from the communitarian ideal of consensualist commonalities.

ISSN 1609-9982 = VERBUM ET ECCLESIA Jrg 22 (1) 2001 
The way in which the Communitarians find a consensus and then proclaim it the essence of the specific group runs the risk of arresting the constant process of redefinition, criticism, change, and creativity that must always remain part of the dialogue. These dangers stem from an attempt to find some ahistorical, acontextual, objective and non-negotiable set of criteria for unifying people. Instead, churches should be seen as associations of individuals based on certain core values or confessional statements. These core values or truth statements should, however, not function as timeless, universal truths devoid of context, but should also be open to interpretation, change and contextual responses. What does this mean for dialogue within the church as organisation?

Empowering church members to become active participants and independent decision-makers within the "universal flesh" of complex interrelationships, can lead to subjectivism and nihilism if the church as organisation or community ceases to play an important role. Therefore, discussion on the confessional elements of a church and its core values is very important. Discussion serves as a way to avoid subjectivist closure and to break through intolerance. Intersubjectivity is also a very effective way to guide members in their development of truth without necessarily labeling some members as heretics. Within the discussion the ongoing tradition of a church, the confessions of believers, and the inputs of both theologians and lay people guide the development of truth without repressing difference. This dialogue must, however, display certain characteristics. Every believer within a church community has a conception of the true, the edifying and the good. The organisation cannot function effectively if these conceptions of the good are not explained by every party, discussed, negotiated and renegotiated for each specific context. The dialogue must therefore be open to ALL involved parties. Furthermore, all involved must communicate openly, honestly, and freely. The existence of unequal power relations (the impossibility of Habermas' ideal speech situation) must be acknowledged and addressed in ways appropriate to the issue and context. It must therefore never be a top-down exercise where certain confessional truths are merely announced to the faith community and within which no discussion or questioning is tolerated. Rather, each member of the church must have some forum where he or she can air views, ask questions, share doubts and fears and develop a very personalised confession of faith. This confession can be an interpretation of what the church as organisation considers its core values. It should overlap, but need not exactly in every respect, conform to the confession of every other member of the faith community. Confession should never be a repressive statement that enforces sameness, it should rather be the opening through which every believer can enter into a very unique relationship with God. The implica- tion of this reasoning would be to use the existing confessional documents of a church as historical examples of confessions of faith, and to encourage individual believers, and even groups of believers, to formulate their own confessions on a regular basis.

\section{CONCLUSION}

It may seem like a huge paradigm shift to move away from the idea that all Christians need to think and be the same in order to uphold the tenet of one holy, catholic church. In my view, it depends on how we chose to think about the relationship between individuals and groups. Unity does not have to suppress difference or dissent. In fact, differences enrich the discourse within churches and keep its confessions alive. It also empowers individuals to be independent thinkers and moral agents in a complex, fast-paced world where it has become impossible to wait for one's church to formulate an official position on an issue before making a decision or taking a stand. Allowing individual deliberation and decision-making need not undermine the unity of churches as communities of believers. It may in fact support a living, contextual faith and responsible, empowered moral decision-making.

\section{Consulted literature}

Brewis, J 1998. Who do you think you are? Feminism, Work, Ethics and Foucault In Hassard, J \& Parker, M (eds) Ethics and Organisations. London: SAGE Publications.

Caputo, J D 1993. Against Ethics. Bloomington: Indiana University Press.

Deleuze, G 1988. Foucault. Minneapolis: University of Minnesota Press.

Foucault, M 1994. Ethics, The Essential Works 1. London: The Penguin Press.

Falzon, C 1998. Foucault and Social Dialogue: Beyond Fragmentation. London: Routledge.

Hassard, J 1993. Postmodernism and Organizational Analysis: An Overview. In Hassard, J \& Parker, M (eds) Postmodernism and Organisations. London. SAGE Publications.

Kirsten, J 1988. Die postmoderne projek: Aspekte van die Hedendaagse Afskeid van die Moderne. Suid-Afrikaanse Tydskrif vir Wysbegeerte, 7(1):18-34.

Lakoff, G \& Johnson, M 1999. Philosophy in the Flesh. The embodied mind and its challenge to Western thought. New York: Basic Books.

Levinas, E 1985. Ethics and Infinity. Pittsburg: Duquesne University Press

Lyotard, J 1984. The Postmodern Condition. A Report on Knowledge. Manchester: Manchester University Press.

Linstead, S 1993. Deconstruction in the Study of Organizations. In Hassard, J \& Parker, M (eds) Postmodernism and Organisations. London. SAGE Publications.

Parker, M 2000. Organizational Culture and Identity. London: SAGE Publications Rorty, R 1994. Objectivity, Relativism and Truth. Philosophical Papers. Cambridge: Cambridge University Press. 
Streng, F J 1993. Cultivating Problems. In Darling-Smith, B. (ed.) Can Virtue be Taught? Notre Dame: University of Notre Dame Press.

Taylor, C 1994. The Politics of Recognition. In Taylor, C \& Gutman, A Multiculturalism: Examining the Politics of Recognition. Princeton: Princeton University Press. 